Kriz Dergisi 2(1): 205-208

\title{
BIRINCI BASAMAKTA RUHSAL SAĞLIK VE BOZUKLUKLAR
}

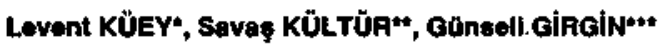

Ruhsal/Zihinsel sorun, belitti ve bozukluklar yol açtıkları bireysel ve toplumsal yitimler nedeniyle ciddi bir sağlık/toplum sağlığı sorunu konumundadır. Bu sorunların çözümünde ruhsal sağlık hizmetlerinin genel/temel sağlık hizmetleri ile bütünleştirilmesi yeterli degilse de, gerekll bir ön koşuldur. Birinci basamak sağlık ekibi ve bu ekibin lideri konumundaki pratisyen hekimler anılan bütünleştirme sürecinde can alıcı önem taşır.

Bu düşüncelerden hareketle, İzmir Atatürk Devlet Hastanesi Psikiyatri Kliniği, Izmir Psikodrama Grup Psikoterapisi Derneği ve Izmir ì Sağlık Müđürlüğü İşbirliği ile Izmir ili Birinci Basamak Hekimlerini Kapsayan Birinci Basamakta Ruhsal Sağlık ve Bozukluklar konulu bir sürekli eğitim projesi geliştirilmiştir. Bu bildiride, seminer uygulamaları Mart ayı başında tamamlanmış olan projenin planlama, uygulama ve degerlendirme aşamaları tanıtılmaktadır.

\section{AMAC}

Bu eğitim projesinde birinci basamak hekimlerinin ruhsal sağlık ve bozukluklar konusunda: 1) Bilgi ve becerilerinin geliştirilmesi; 2) Konuyla ilgili duyarlılıklarının arttırıması

- Psikiyatr, Doc.. Dr., Izmir Atalürk Deviel Hastanesi Psikiyatri Klininit

* Psiklyatr, Prot. Dr., Izmir Atatürk Devlet Hastanesi Psikiyatri Klinizigi

4 Psikolog, İzmir li Sağlık Mũdūrlüğü Ruh Sağłığı Şubesi. amaçlanmıştır. Ayrıca, proje kapsamında Birinci Basamakta Ruhsal Sağlık ve Bozukłuklar adlı bir yayın hazırlanması tasarlanmaktadır.

\section{YÖNTEM}

Hedef Kltle: Izmir ili birinci basamak hekimleridir. Proje Metropol Sağlik ocaklarından ve ilçe sağlık ocaklarından birer asil ve birer yedek olmak üzere toplam yaklaşık 160 pratisyen hekimin gönüllü katılımıyla yürütülmektedir.

Eglticl Kadro ve Konular: Eğitici kadro ve konular, 1) Daha ónceki benzer eğitim programı; 2) Sağłık ocağı hekimlerinin görüşleri; 3) Psikiyatri kliniklerinin (izmir Atatürk Devlet Hastanesi Psikiyatri Kliniği, Ege Üniv. Tıp. Fak. Psikiyatri Ana bilim dalı, Dokuz Eylül Üniv. Tıp Fak. psikiyatri ana bilim dalı) görüşleri dikkate ałnarak saptanmıştır. Eğiticiler İzmir ilinde çalışıyor olma, saptanan konularda eğitim/araştırma etkinliğinin bulunması ve gönüllülük ölçütleri ışığında belirlenmiş uzmanlardan oluşmaktadır. Konular ve eğitim kadrosu Tablo 1'de verilmiştir.

Egltlm Materyalt: Eğitimde kullanılacak materyal amaca uygun biçimde her konuyu işleyecek uzman tarafından hazırlanmıştır. Bu materyalin hazıflanmasında birinci basamak hekiminin kuramsal ve pratik ihtiyaçları ile eğitim ilkeleri dikkate alınmaya çalışılmıştır. Bu eğitim materyali uygulama sonrası gözden geçirilerek 
TABLO 1: IŞLENEN KONULAR VE EĞITIM KADROSU.

1. SAGLIK HIZMETLERINDE BIRINCI BASAMAK HEKIMININ YERI PROF. DR. GAZANFER AKSAKOĞLU

BIRINCI BASAMAK HEKIMININ RUHSAL SAĞLIK HIZMETLERINDE IŞLEVi DOÇ. DR. LEVENT KÜEY

2. HASTA HEKIM ILIŞKISI

PROF. DR. AYŞEN BAYKARA

3. ÇOCUKLUK VE ERGENLIK ÇAĞı RUHSAL ÖZELLIKLERI

PROF. DR. CAHIDE AYDIN

4. BIRINCI BASAMAKTA NEVROTIK BOZUKLUKLAR

PROF. DR. NURI DOĞAN ATALAY

5. BIRINCI BASAMAKTA DEPRESIF BOZUKLUKLAR

DOÇ. DR. LEVENT KÜEY

6. BIRINCI BASAMAKTA BIPOLAR BOZUKLUKLAR

DOÇ. DR. SIMAVI VAHIP

7. BIRINCI BASAMAKTA PSIKOTIK BOZUKLUKLAR

PROF. DR. SAVAŞ KÜLTÜR

8. BIRINCI BASAMAKTA ORGANIK KÖKENLI RUHSAL BOZUKLUKLAR

YARD. DOÇ. DR. ERHAN BAYRAKTAR

9. BIRINCI BASAMAKTA ALKOL VE MADDE BAĞIMLILIKLARI

ÖG. GÖR. DR. BEYAZIT YEMEZ, UZM. DR. HAKAN ÇOŞKUNOL

10. BIRINCI BASAMAKTA PSIKOSOMATIK BOZUKLUKLAR

UZM. DR. EROL OZMEN

11. BIRINCI BASAMAKTA KIŞiLiK BOZUKLUKLARI

PROF. DR. SOLI SORIAS

12. BIRINCI BASAMAKTA ACIL PSIKIYYTRIK DURUMLAR

UZM. DR. AYHAN EĞRILMEZ

13. PSIKOFARMAKOLOJIK AJANLAR VE KULLANIMLARI

PROF. DR. IŞIK TUĞLULAR,

14. BIRINCI BASAMAKTA PSIKOFARMAKOLOJIK TEDAVILER

PROF. DR. ZELIHA TUNCA

15. BIRINCI BASAMAKTA ÇOCUKLUK VE ERGENLIK RUHSAL SORUNLARI YARD. DOÇ. DR. SUHA MIRAL

16. CINSEL YAŞAM VE SORUNLARI

UZM. DR. EMRE KAPKIN

17. YAŞLILIK ÇAĞı VE BIRINCI BASAMAKTA RUHSAL SORUNLARI

DOÇ. DR. ILKIN IÇELLI

18. UYUM GÜÇLÜĞÜ YARATAN YAŞAM OLAYLARI

DOÇ. DR. OYA SORIAS

19. KIMLIK VE BIRINCI BASAMAK HEKIMININ MESLEKI KIMLIK SORUNLARI

PSK. GÜNSELI GIRGIN/DOÇ. DR. LEVENT KÜEY 
yayına dönôştürülecektir. Materyalin hazırlanmasında işlenen konu elverdiği ölçüde uyulması beklenen konu başıłıları Tablo 2'de verilmiştir.

Uygulama: Katılanlar yaklaşık $80^{\prime}$ er kişilik 2 kümeye bölünmüştür. Konular her küme için ayrı ayrı yaklaşık 5 aylık süre içinde, haftada bir kez, 45'er dakikalık 2 seminer biçiminde, toplam 30 saattik (20x1.5=30) eğitim sürecinde işlenmiştir.

\section{DEĞERLENDiRME}

Bu eğitimin etkinliği katılanların eğitimin kendi güncel pratikleri üzerindeki etkisine dair düşünceleri ile ölçülmektedir. Bu amaçla hazırlanmış anket (Tablo 3) programın başında ve bitiminde uygulanmıştır; bu etkilerin izlemi için aitı ay sonra tekrar uygulanacaktır. Diğer yandan, katılanlar eğitimin sonunda, uygun bir form ile her semineri içerik, biçim ve varolan bilgilerine katkısı açılarından değerlendirmiş ve programın olumiu/olumsuz yaniarını açık uçlu sorulara yanıt vererek belirtmişlerdir. Bu değerlendirmelerden aynı zamanda seminer notlarının yayına dönüştürülmesinde de yararlanılacaktır. Eğitim programı sonunda bir kattım belgesi verilmiştir.

\section{ZAMANLAMA VE iş AKIŞı}

Bu eğjtim projesinin ön taslağı Ocak 1993'de hazırlanmış ve İmir ili sağlık ocaklarına ve psikiyatri kliniklerine gönderilerek görüş ve öneriler alınmıştır. Bunlar gözden geçirilerek proje protokolü oluşturuimuş ve eğitim kadrosu ile yapılan toplantılarda kesinleştirilmiştir. Seminerlerin uygulanışı (Ekim '93 - Mart '94) arasında gerçekleştirilmiştir. Önümüzdeki dönemde de seminer notlarının yeniden gözden geçirilmesi ve ruhsal sağlık ve bozuklukların pratisyen hekimin ihtiyaçlarına göre işlendiği bir kitap hazırianması planlanmaktadır. Bu proje Izmir ili yerel olanakları çerçevesinde planlanmış ve yürütülmüştür.

TABLO 2: KONU ALT BAŞLIKLARI

(1) GiRiş

* Tanım, tarihçe

"Epidemiyoloji

*Etjyoloji

(2) KLINIK ÖZELLIKLER

" Klinik özellikler, belirti ve bulgular

" ilişkili tanı kategorileri, alt tipler, ayıııcı tanı

- Yardimci incelemeler

* Seyir, prognoz

(3) ELE ALMA, YÖNLENDIRME VE SAGALTIM

* Sağaltım ilkeleri, uygulamaları

*Ailenin yönlendirilmesi

" Birincil korumaya yönelik ilke ve önlemler

* İleme ve üçüncül korumaya yönelik ilke ve önlemler

(4) KONUYLA ILGILI YASAL VE SOSYAL SORUNLAR

(5) TEST

Bir vaka (case) ya da durum (situation) öyküsü ve bununla ilgili 3-5 çoktan seçmeli soru

AYRICA ÇERÇEVE IÇINE KONMAK ÜZERE:

* Tanı ölçütleri

* Konuyla ilgili yaygin yanlış inanışlar

* Vurgulanmasi istenen özel konular 


\section{TABLO 3: DEĞERLENDIRME}

(1) Son altı ay içinde koyduğunuz ruhsal bozukłuk tanısı tüm tanılarınızın yaklaşık yüzde kaçını oluşturmaktadır?\%:..

(2) Son altı ay içinde yazdığınız psikofarmakolojik ajanlar tüm ilaçlarınızın yaklaşık yüzde kaçını oluşturmaktadır? \%...

(3) Son altı ay içinde tüm hasta sevklerinizin yaklaşık yüzde kaçı psikiyatriste sevk biçimindedir? \%...

(4) Son altı ay içinde hospitalizasyon amacıyla yaptığınız sevklerin yaklaşık yüzde kaçı ruh sağığı ve hastalıklan hastanesine/psikiyatri kliniğine sevk biçimindedir? $\% .$.

(5) Son altt ay içinde ruhsal saghlk ve bozukluklarla ilgili herhangl bir aktiviteye (panel, konterans, kongre vb.) katıldysanız belirtiniz... 